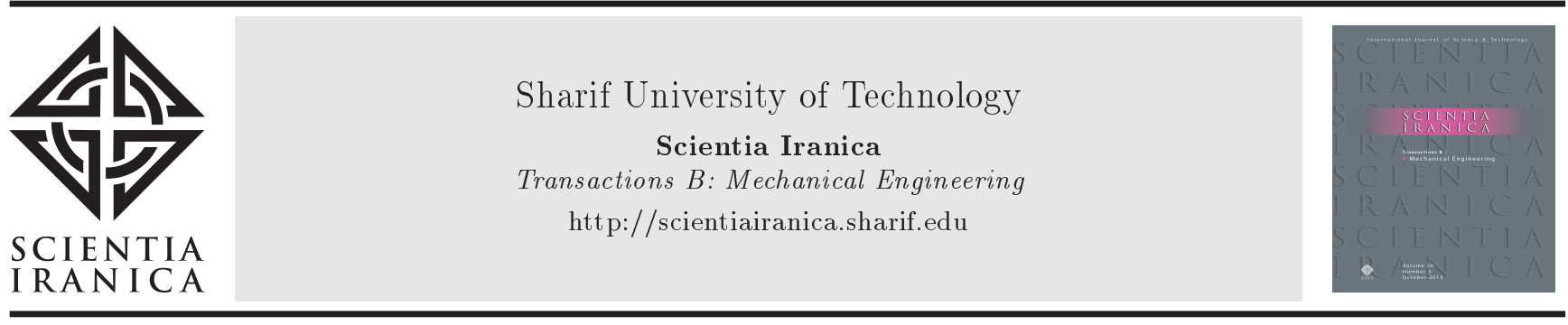

Research Note

\title{
Numerical analysis of vibration and transient behaviour of laminated composite curved shallow shell structure: An experimental validation
}

\author{
S.S. Sahoo, C.K. Hirwani, S.K. Panda*, and D. Sen \\ Department of Mechanical Engineering, National Institute of Technology, Rourkela, 769008, India.
}

Received 30 January 2017; received in revised form 13 April 2017; accepted 17 July 2017

\author{
KEYWORDS \\ Experimental \\ vibration; \\ Carbon/epoxy \\ composite; \\ HSDT; \\ FEM; \\ ANSYS; \\ Transient behaviour.
}

\begin{abstract}
The natural frequency and transient responses of carbon/epoxy layered composite plate structure were analysed through the instrumentality of two higher-order mid-plane kinematic models in this article. The mathematical formulation of the layered composite structure was further utilised to develop a computer programme in MATLAB15.0 to evaluate the mentioned responses. The practical relevance of the present higherorder models was established via comparing the present numerical results computed using suitable MATLAB computer code with the in-house experimental test data. Additionally, the fundamental frequency and transient responses of the carbon fibre-reinforced epoxy composite plate structure were simulated via finite-element package (ANSYS) by means of the ANSYS Parametric Design Language (APDL) code. The simulated frequencies were compared with those of the present experimental and MATLAB results. Finally, the significance of the proposed higher-order kinematics was established via solving a different kind of illustrations to investigate the influence of various geometrical and material parameters on the dynamic responses of layered composite structure, discussed in detail.

(C) 2018 Sharif University of Technology. All rights reserved.
\end{abstract}

\section{Introduction}

The quest of designers to achieve lightweight structural materials with reliable strength and stiffness properties has led to the development of advanced materials, such as laminated composite. Owing to its superior characteristics, laminated structures possess many applications in high-performance engineering fields, such as aerospace, marine, automotive, and civil infrastructure. The layered composites can provide tailor-made

*. Corresponding author. Tel.: +91661 2462529

E-mail addresses: sushree.sahoo101@gmail.com (S.S.

Sahoo); chetanhirwani111@gmail.com (C.K. Hirwani);

call2subrat@gmail.com, pandask@nitrkl.ac.in (S.K. Panda);

deeprocool@gmail.com (D.Sen).

doi: $10.24200 /$ sci.2017.4346 properties due to their stacking sequence and layer thickness that, in turn, enhance the final structural performances during their service condition. Today, the laminated composite panel that creates the necessity for the accurate analysis and design of the final finished product rapidly replaces most of the structural components. In general, most of the structures are exposed to the low/high amplitude of vibration under the dynamic loading, and accurate prediction of the desired responses (fundamental frequency and transient response) is of great importance. The Finite-Element Method (FEM) is a potential method established as a versatile numerical tool from the last few decades to analyse the laminated structural problems due to their inherent materials and geometrical complexities. Many studies on the development of the numerical model are reported where the structural responses are obtained 
using different theories, such as classical as well as firstand higher-order shear deformation theories, including the modified kinematic models, for accurate analysis. Further, to improve the accuracy of the numerical results and reduce the experimental cost, studies have continued every now and then. Some of the very relevant and important studies have been reviewed and presented in the following line, and few key deficiencies in the former studies are pointed out.

Mallikarjuna and Kant [1] proposed a FiniteElement (EF) model in higher-order shear deformation theory to analyse the dynamic behavior of the layered composite plate structure. Similarly, the FEM solutions for frequency values of the doublycurved shell panel were computed by Chakravorty et al. [2] using the First-order Shear Deformation Theory (FSDT). Further, the fundamental frequency responses of the fibre-reinforced layered polymer composite plate were examined by Chakraborty and Mukhopadhyay [3] experimentally (impact excitation) and numerically using commercial FE package (NISA). Ahmadian and Zangeneh [4] analysed the dynamic characteristics of the rectangular layered composite plate by means of a superelement. The dynamic responses of thick multilayered composite flat/curved panel and sandwich plate were reported using the new HSDT $[5,6]$ kinematic model. Further, Cugnoni et al. [7] computed the experimental modal test of Glass/Polypropylene composite plate and performed the validation test by comparing them with numerical results of the thin- and thicklayered composite shell panels computed via FSDT as well as the HSDT kinematic models. Tornabene et al. [8] obtained the free vibration responses of layered composite shell panel using a 2D higher-order general formulation. Jeyaraj et al. [9] analysed the vibration and acoustic responses of an isotropic rectangular plate under the harmonic load, including the thermal environment, using different types of commercial FE packages (ANSYS and SYSNOISE). Mehar et al. [10] computed the natural frequency responses of the functionally graded carbon nanotube (FG-CNT) composite plate using the HSDT mid-plane kinematics. The free vibration and time-dependent displacement behaviour of the layered structure were examined based on the FSDT kinematics using an eight-node quadrilateral serendipity element [11-13]. Later, Shokrollahi and Shafaghat [14] examined the dynamic behaviours of the hybrid metal-composite thick trapezoidal plates using global Ritz method in FSDT kinematics. The displacement kinematic using FSDT was also considered by Kerur and Ghosh [15] to compute the frequency responses of the layered composite panel and the active vibration control with integrated Active Fiber Composite (AFC) layer. Kumar and Raju [16] analysed the dynamic responses of the cross- and angle-ply layered composite structures via a mathematical model based on HSDT. The dynamic behaviour of the square laminated plate with edges containing randomly and unidirectionally aligned short fibers was investigated by Eruslu and Aydogdu [17] using the FSDT kinematics. Similarly, the static and dynamic responses of the layered composite shallow shell panel using higher-order FEM model were examined by Sahoo et al. [18] and validated with the corresponding experimental values. Hirwani et al. [19] reported theoretical and experimental vibration analyses of debonded shell structure using different kinematic models in association with FEM. The free vibration behaviour of the layered composite beam was analysed by Li et al. [20] using refined HSDT kinematics. The static and dynamic [21-34] characteristics of layered composite as well as sandwich structure using mathematical model developed based on various theories such as new trigonometric plate [35-37], new sinusoidal higher-order plate [38,39], and hyperbolic shear deformation theory $[40,41]$ were analysed by Tounsi and his co-authors. The Large-amplitude dynamic behaviour of curved panel was reported by Shooshtari and Razavi [42] using a Donnell shell theory. Milan et al. [43] computed the dynamic characteristic of the carbon/epoxy layered composite flat plate structure using ANSYS.

It can be clearly observed from the above reviews that many numerical attempts have been already made to investigate the dynamic responses of the layered structure via different numerical as well as analytical techniques. It should be noted that the investigation of the fundamental frequency, including the timedependent displacement responses of the layered composite structure, using the HSDT model and the subsequent validation with experimental and simulation (ANSYS) results, is very limited in numbers. Hence, to address the issue and overcome the shortcomings of the former researchers, the current study aims to work as a bridge between the gaps. In this regard, the present research focuses on the development of numerical model to compute the fundamental frequencies and timedependent deflections of the layered composite structure using two different HSDT models. Further, the responses are evaluated using the homemade computer code in MATLAB software and experiments on carbon/epoxy layered composite. The responses obtained using the theoretical and experimental are utilised for a comparison purpose to establish the requirement of the currently developed higher-order models. Again, the structural responses are computed via simulation model through structural simulation software (ANSYS) and compared with both the numerical and experimental values. Finally, sensitivity analysis is carried out on different parameters, such as shell panel geometries (cylindrical, spherical, flat, hyperboloid, and elliptical), including the other geometrical and material parame- 

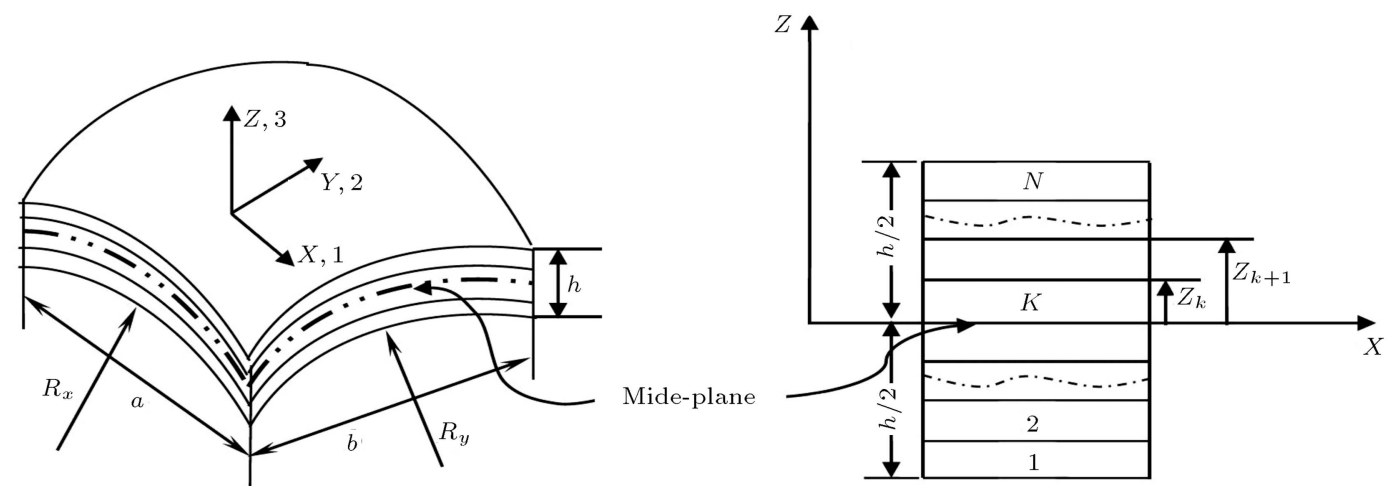

Figure 1. Geometry of laminated curved panel.

ters, to show their effects on the frequency and timedependent displacement responses.

\section{Theoretical formulation}

\subsection{Geometry of the panel}

For the present investigation, a layered composite doubly-curved shell panel with $N$ number of orthotropic layers of equal thickness has been considered, as presented in Figure 1. The following geometrical parameter of the panel is considered: the length as $a$, the breadth as $b$, and the thickness as $h$. The displacement continuity within the layered composite is considered based on HSDT kinematics [44], where the in-plane displacement functions are defined as a cubic function of thickness co-ordinate, and the displacement field function in the thickness direction is assumed to be constant or linearly varying throughout the thickness. In addition, the necessary assumptions on the current modelling purpose (uniform layer thickness, bonding between the layers, elastic behaviour of individual composite constituent, etc.) are made, similar to the reference [44].

\subsection{Displacement field and strain displacement relation}

The displacement continuum for the first HSDT model (Model-1) is presented in Eq. (1), where displacement function in the thickness direction is considered constant through the thickness:

$$
\begin{aligned}
u(x, y, z, t)= & u_{0}(x, y, t)+z \theta_{x}(x, y, t)+z^{2} \phi_{x}(x, y, t) \\
& +z^{3} \lambda_{x}(x, y, t), \\
\nu(x, y, z, t)= & \nu_{0}(x, y, t)+z \theta_{y}(x, y, t)+z^{2} \phi_{y}(x, y, t) \\
& +z^{3} \lambda_{y}(x, y, t), \\
w(x, y, z, t)= & w_{0}(x, y, t) .
\end{aligned}
$$

Further to the above, another HSDT kinematic model say, Model-2, is also employed for the current math- ematical modelling of the layered composite panel structure, where the displacement function through the thickness is assumed to be varying linearly [5]:

$$
\begin{aligned}
u(x, y, z, t)= & u_{0}(x, y, t)+z \theta_{x}(x, y, t)+z^{2} \phi_{x}(x, y, t) \\
& +z^{3} \lambda_{x}(x, y, t), \\
\nu(x, y, z, t)= & \nu_{0}(x, y, t)+z \theta_{y}(x, y, t)+z^{2} \phi_{y}(x, y, t) \\
& +z^{3} \lambda_{y}(x, y, t), \\
w(x, y, z, t)= & w_{0}(x, y, t)+z \theta_{z}(x, y, t),
\end{aligned}
$$

where $u, \nu$, and $w$ represent the translation of any point (within the laminate) along $x, y$, and $z$ directions, respectively; $t$ denotes the time, $u_{0}, \nu_{0}$, and $w_{0}$ are the mid-plane displacements, $\theta_{x}$ and $\theta_{y}$ denote the rotations of the normal to the mid-plane about $y$ and $x$ directions, respectively. The rest of the terms $\phi_{x}, \phi_{y}, \lambda_{x}, \lambda_{y}$, and $\theta_{z}$ are the higher-order terms of Taylor series expansion, considered to maintain the actual profile of shear stress (parabolic variation) through the thickness of the layered composite structure.

Further, another model is developed in ANSYS package via the batch input technique of ANSYS Parametric Design Language (APDL), code named as Model-3. The simulation model is discretised using a well-defined SHELL-281 element. The SHELL-281 element is an eight-node element with six degrees of freedom at each node and is suitable for the analysis of thin- to moderately thick-layered structures. The displacement kinematics of the simulation model based on FSDT [45] is shown in Eq. (3):

$$
\begin{aligned}
& u(x, y, z, t)=u_{0}(x, y, t)+z \theta_{x}(x, y, t), \\
& \nu(x, y, z, t)=\nu_{0}(x, y, t)+z \theta_{y}(x, y, t), \\
& w(x, y, z, t)=w_{0}(x, y, t)+z \theta_{z}(x, y, t) .
\end{aligned}
$$

Further, the constitutive equation is expressed in the following line for any $k$ th lamina within the laminate 
which is oriented at an arbitrary angle " $\theta$ " about any principal material axes:

$$
\left\{\sigma_{i j}\right\}=\left[\bar{Q}_{i j}\right]\left\{\varepsilon_{i j}\right\},
$$

$\left\{\sigma_{i j}\right\},\left\{\varepsilon_{i j}\right\}$, and $\left[\bar{Q}_{i j}\right]$ represent the stress tensor, strain tensor, and reduced stiffness matrix, respectively. The expansion of the strain tensor can be presented further as follows:

$$
\left\{\varepsilon_{i j}\right\}=\left\{\begin{array}{c}
\varepsilon_{x x} \\
\varepsilon_{y y} \\
\varepsilon_{z z} \\
\gamma_{x y} \\
\gamma_{x z} \\
\gamma_{y z}
\end{array}\right\}=\left\{\begin{array}{l}
\left(\frac{\partial u}{\partial x}+\frac{w}{R_{x}}\right) \\
\left(\frac{\partial v}{\partial y}+\frac{w}{R_{y}}\right) \\
\left(\frac{\partial w}{\partial z}\right) \\
\left(\frac{\partial u}{\partial y}+\frac{\partial v}{\partial x}\right) \\
\left(\frac{\partial u}{\partial z}+\frac{\partial w}{\partial x}-\frac{u}{R_{x}}\right) \\
\left(\frac{\partial v}{\partial z}+\frac{\partial w}{\partial y}-\frac{v}{R_{y}}\right)
\end{array}\right\}
$$

where $R_{x}$ and $R_{y}$ are the principal radii of curvature in $x$ and $y$ axes, respectively.

\subsection{Finite-element formulation}

The FEM is a potential tool to analyse the structural responses of the layered composite structure with complex geometry. In the present formulation, the necessary discretisations of the proposed model of the layered structure have been performed through the use of suitable FEM steps using a nine-node isoparametric element. Now, " $d$ " as a displacement vector at an arbitrary point on the mid-surface of the panel structure for all three models can be expressed in a generalised form as follows:

$$
d=\sum_{i=1}^{n} N_{i}(x, y) d_{i}
$$

where $\left\{d_{i}\right\}=\left\{u_{0_{i}} v_{0_{i}} w_{0_{i}} \theta_{x_{i}} \theta_{y_{i}} \phi_{x i} \phi_{y i} \lambda_{x i} \lambda_{x i}\right\}^{T},\left\{d_{i}\right\}=$

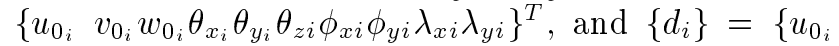
$\left.v_{0_{i}} w_{0_{i}} \theta_{x_{i}} \theta_{y_{i}} \theta_{z i}\right\}^{T}$ are displacement field functions for the corresponding models (Model-1, Model-2, and Model-3) utilised in the current analysis. Similarly, $N_{i}$ represents the shape functions of the $i$ th node.

Now, the strain tensor can be represented in the matrix form as follows:

$$
\{\varepsilon\}=[T]\{\bar{\varepsilon}\},
$$

where $[T]$ and $\{\bar{\varepsilon}\}$ denote the thickness coordinate matrix and mid-plane strain. Now, the mid-plane strain vector can be further explored and written as follows:

$$
\{\bar{\varepsilon}\}=\left[B_{L}\right]\left\{d_{i}\right\},
$$

where $\left[B_{L}\right]$ denotes the matrix of a general strain displacement relation according to the type of displacement field model.
The total strain energy of the laminated panel is expressed in the following line using the strain and stress tensors and is expressed as follows:

$$
U=\frac{1}{2} \iint\left[\int_{-h / 2}^{+h / 2}\{\varepsilon\}^{T}\{\sigma\} d z\right] d x d y .
$$

Eq. (9) can be modified further by substituting stress and strain relation, presented as follows:

$$
U=\frac{1}{2} \iint\left(\{\bar{\varepsilon}\}^{T}[D]\{\bar{\varepsilon}\}\right) d x d y
$$

where $[D]=\int_{-h / 2}^{+h / 2}[T]^{T}\left[Q_{i j}\right][T] d z$.

The kinetic energy of the layered panel is presented in terms of mass density and velocity as follows:

$$
T=\frac{1}{2} \int_{V} \rho\{\dot{d}\}^{T}\{\dot{d}\} d V
$$

where $\{\dot{d}\}$ and $\rho$ represent the global velocity vector and mass density, respectively.

The free vibrated composite panel equation is formed using the necessary energy functional and solved via Hamilton's principle. Finally, the equation of motion is expressed in the following line:

$$
d \int_{t_{1}}^{t_{2}}(T-U) d t=0
$$

where $T$ represents the kinetic energy, and $U$ represents the strain energy.

Now, Eq. (12) can be rewritten by substituting value of $d, T$, and $U$ from Eqs. (6), (10), and (11):

$$
[M]\left\{\ddot{d}_{i}\right\}+[K]\left\{d_{i}\right\}=0,
$$

where $[M],[K], \ddot{d}_{i}$, and $d_{i}$ denote the mass matrices, stiffness matrix, acceleration, and the displacement, respectively. The stiffness and mass matrix can be written further as follows:

$$
\begin{aligned}
& {[K]=\int_{A}\left[B_{L}\right]^{T}[D]\left[B_{L}\right] d A,} \\
& {[M]=\int_{A}[N]^{T}[N] \rho d A .}
\end{aligned}
$$

Further, the final governing equation used to evaluate the fundamental frequency response of the system in an eigenvalue form can be expressed as follows:

$$
\left([K]-\omega^{2}[M]\right)\{d\}=0,
$$




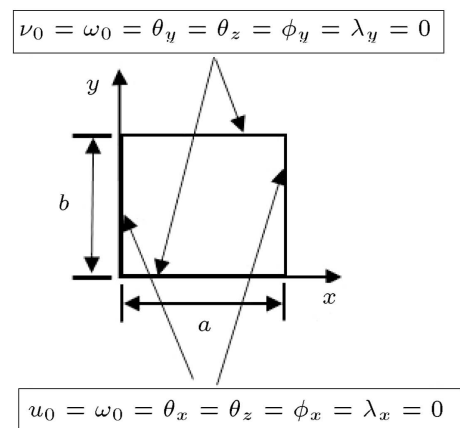

(a)

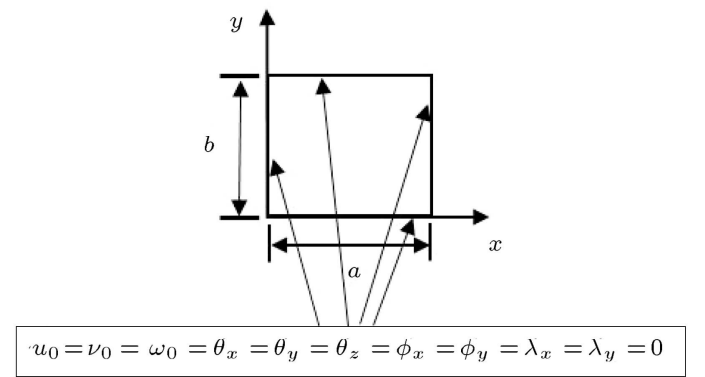

(b)

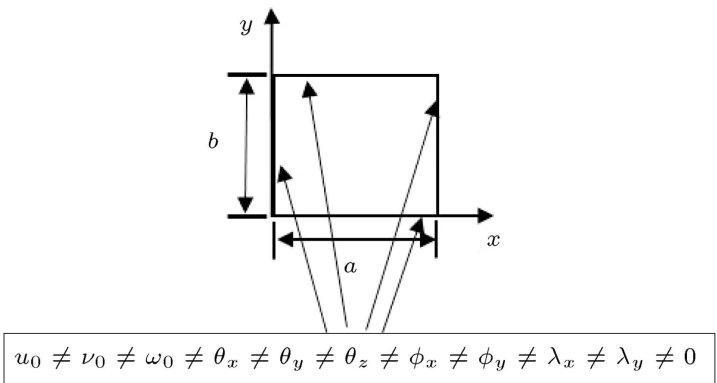

(c)

Figure 2. Representation of end conditions: (a)

Simply-supported, (b) clamped, and (c) free end condition.

where $\omega$ is the fundamental frequency.

Eq. (15) can be solved by applying different sets of constraint conditions (Figure 2(a)-(c)) at the edges in order to decrease the number of unknowns and avoid any rigid body motion.

\subsection{Newmark's integration scheme for transient analysis}

In order to obtain the time-dependent deflection responses, Newmark's integration scheme has been employed. The governing equation of the transient responses accounts for the effects of the inertia, damping, and static deflection. The final form of the governing equation can be presented as follows:

$$
[M] \ddot{d}+[C] \dot{d}+[K] d=[F],
$$

where $[M]$ represents the mass matrix, $[C]$ denotes damping matrix, $[K]$ represents the stiffness matrices, and $[F]$ is the externally applied load vector. Further, the above-mentioned time-dependent motion equation is solved to compute the maximum deflection parameter at the centre of the panel for total time ' $T$ '. The total time is divided into small time zones, e.g. time steps $\Delta t$ and the values are calculated for each time step. Different integration parameters, such as $\alpha, \delta$, and $a_{0}$ to $a_{7}$ of used Newmark's integration, are assumed to be the same as those defined in [46]. The expression for the effective stiffness matrix at each time step is expressed as follows:

$$
[\hat{K}]=[K]+a_{0}[M] .
$$

Similarly, the expression for the final load matrix and successive time step $(t+\Delta t)$ implementation of the present analysis is presented in the following lines:

$$
{ }^{t+\Delta t}[\hat{F}]={ }^{t+\Delta t}[F]+[M]\left(a_{0}{ }^{t} d+a_{2}{ }^{t} \dot{d}+a_{3}{ }^{t} \ddot{d}\right) .
$$

Further, the expression of the displacement, acceleration, and velocity can be presented as follows:

$$
\begin{aligned}
& {[\hat{K}]^{t+\Delta t} d={ }^{t+\Delta t}[\hat{F}],} \\
& { }^{t+\Delta t} \ddot{d}=a_{0}\left({ }^{t+\Delta t} d-{ }^{t} d\right)-a_{2}{ }^{t} \dot{d}-a_{3}{ }^{t} \ddot{d}, \\
& { }^{t+\Delta t} \dot{d}={ }^{t} \dot{d}+a_{6}{ }^{t} \ddot{d}+a_{7}{ }^{t+\Delta t} \ddot{d} .
\end{aligned}
$$

\section{Results and discussion}

The results and their corresponding discussions are reported in three major subsections. In the first section, the consistency and accuracy of the proposed HSDT models are examined via computing the dynamic and free vibration responses of different mesh refinements, which are utilised for the comparison with those of the earlier published responses. Subsequently, the second subsection describes the experimental evaluation of elastic properties and experimental dynamic responses of carbon/epoxy layered composite structure. After the validation of the present numerical model, some new numerical illustrations are computed theoretically to show the importance of the present model and the influence of the other design parameters on the dynamic responses.

\subsection{Stability and accuracy investigation}

The stability of the present numerical models, i.e. Model-1 and Model-2, and the simulation model, i.e. Model-3, has been examined by analysing the vibration and time-dependent deflection responses of layered composite flat plate structure for various mesh sizes, as shown in Figures 3(a) and 3(b), respectively. The nondimensional natural frequencies of simply-supported two-layer and four-layer symmetric cross-ply $\left(0^{\circ} / 90^{\circ}\right)$ layered flat panels for five different thickness ratios are obtained using the geometrical parameter, the same 


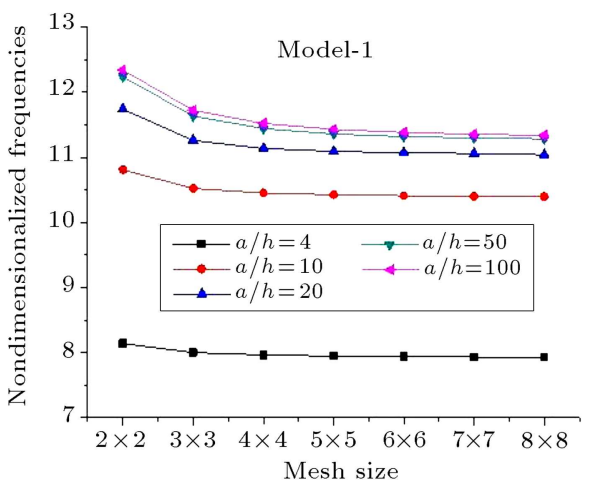

(i)

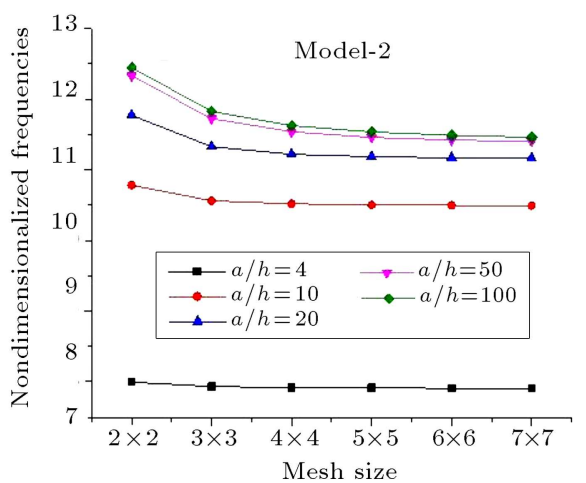

(ii)

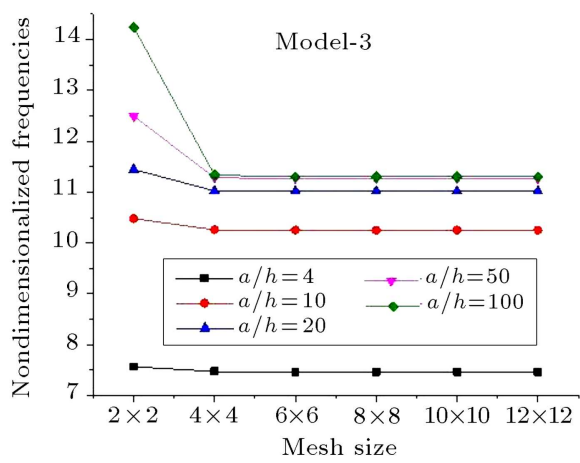

(iii)

Figure 3(a). Convergence of non-dimensional frequency of a simply-supported two-layered cross-ply laminated flat panel: (i) Model-1, (ii) Model-2, and (iii) Model-3.

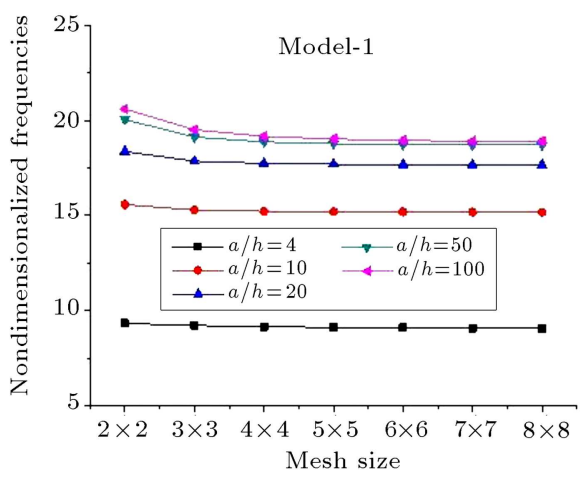

(i)

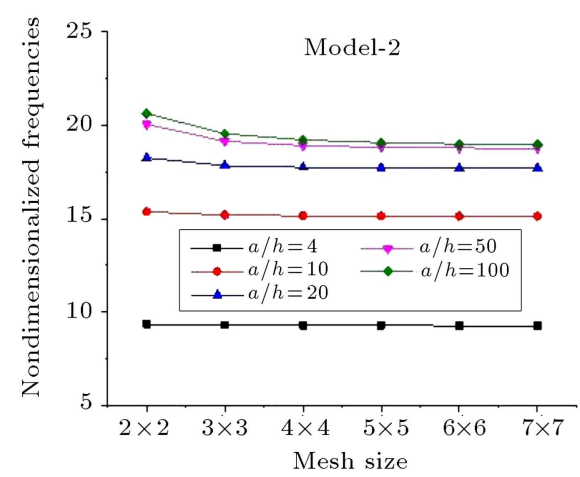

(ii)

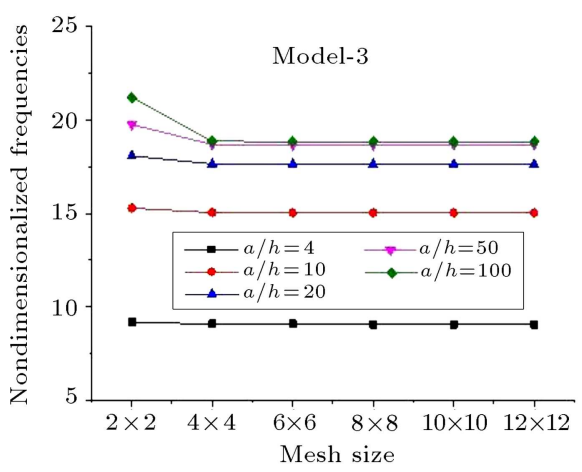

(iii)

Figure 3(b). Convergence of non-dimensional frequency of a simply-supported four-layered symmetric cross-ply symmetric laminated flat panel: (i) Model-1 (ii) Model-2, and (iii) Model-3. 
Table 1. Non-dimensional frequency of a simply-supported two-layered and four-layered symmetric cross-ply laminated flat panels.

\begin{tabular}{|c|c|c|c|c|c|c|c|c|}
\hline \multirow[b]{2}{*}{$\begin{array}{c}\text { Lamination } \\
\text { Scheme }\end{array}$} & \multirow[b]{2}{*}{$a / h$} & \multicolumn{7}{|c|}{ Non-dimensional frequency } \\
\hline & & Model-1 & Model-2 & Model-3 & $\begin{array}{c}\text { Analytical } \\
{[5]}\end{array}$ & $\begin{array}{c}3 D \\
\text { Elasticity } \\
{[47]}\end{array}$ & $\begin{array}{c}\text { Analytical } \\
{[48]}\end{array}$ & $\begin{array}{c}\text { Analytical } \\
{[49]}\end{array}$ \\
\hline \multirow{5}{*}{$\left(0^{\circ} / 90^{\circ}\right)$} & 4 & 7.9398 & 7.9043 & 7.4616 & 7.8908 & 8.3546 & 8.3546 & 8.0889 \\
\hline & 10 & 10.4134 & 10.4955 & 10.2501 & 10.4156 & 10.5680 & 10.5680 & 10.4610 \\
\hline & 20 & 11.0730 & 11.1693 & 11.0126 & 11.0509 & 11.1052 & 11.1052 & 11.0639 \\
\hline & 50 & 11.3221 & 11.4209 & 11.2631 & 11.2537 & 11.2751 & 11.2751 & 11.2558 \\
\hline & 100 & 11.3854 & 11.487 & 11.3005 & 11.2837 & 11.3002 & 11.3002 & 11.2843 \\
\hline \multirow{5}{*}{$\left(0^{\circ} / 90^{\circ}\right)_{\mathrm{s}}$} & 4 & 9.0866 & 9.2694 & 9.0672 & 9.271 & 9.3235 & 10.2032 & 9.3949 \\
\hline & 10 & 15.1775 & 15.134 & 15.0329 & 15.0949 & 15.1073 & 15.9405 & 15.1426 \\
\hline & 20 & 17.6754 & 17.7127 & 17.6301 & 17.6434 & 17.6457 & 17.9938 & 17.6596 \\
\hline & 50 & 18.7214 & 18.7833 & 18.6754 & 18.6713 & 18.6718 & 18.7381 & 18.6742 \\
\hline & 100 & 18.9384 & 19.0044 & 18.8426 & 18.8355 & 18.8356 & 18.8526 & 18.8362 \\
\hline
\end{tabular}

as in [5] and M1 properties. The non-dimensional natural frequency throughout the analysis is obtained via the formulae: $\bar{\omega}=\frac{\omega a^{2}}{h} \sqrt{\frac{\rho}{E_{t}}}$, where $\omega$ represents the fundamental frequency responses, if not stated otherwise. It has been seen from the convergence test that the responses are converging well with different mesh sizes. Accordingly, a mesh size of $(6 \times 6)$ is utilised for further investigation. In addition, the responses of five side-to-thickness ratios $(a / h=4,10,20,50$ and 100) are obtained, and then they are compared with those of the analytical and numerical responses of references [5,47-49], as depicted in Table 1. Based on the comparison, it is inferred that the present results show good agreement with the published results of different solution approaches.

\subsection{Experimental validation}

In the present section, the free vibration responses are obtained experimentally for carbon/epoxy angleply flat panels of two- and four-layer types under two support conditions (SFSF and CFFF), and they are compared with the present FE responses obtained using all the three models. The comparison study is depicted in Table 2. In this example, the elastic properties of two- and four-layer composites are examined experimentally, namely M2 and M3, as presented in Table 3. For the evaluation, three specimens (along longitudinal, transverse, and inclined directions $\left(45^{\circ}\right.$ to the longitudinal direction)) are prepared following the instruction given in the ASTM D3039/D3039M [50]. The specimens are tested using Universal Testing Machine (UTM) INSTRON-1195 at NIT, Rourkela. All the tests have been performed by fixing the loading rate as $1 \mathrm{~mm} / \mathrm{min}$. The UTM and the broken (tested) specimens of the carbon/epoxy layered composite are

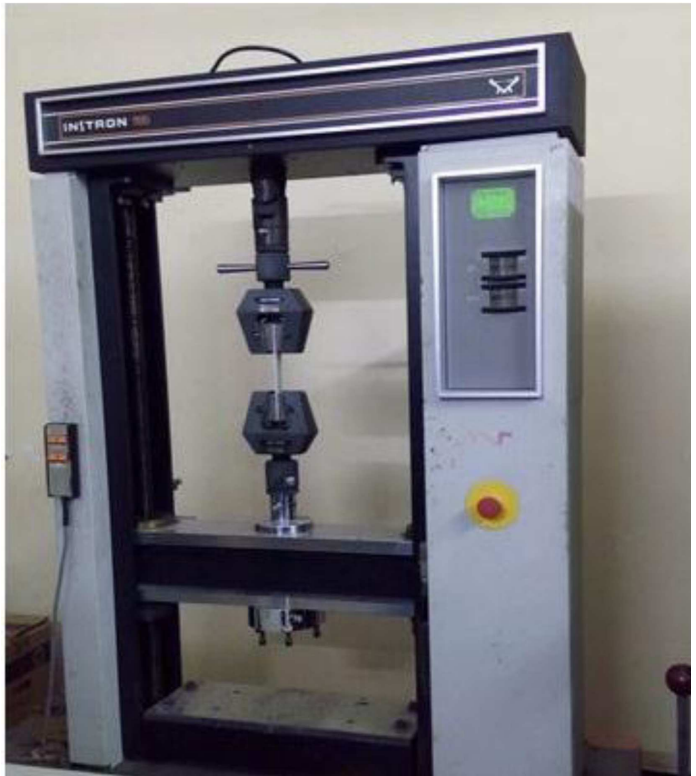

Figure 4(a). Tensile testing machine (INSTRON 1195).

provided in Figures 4(a) and 4(b), respectively. It is necessary to mention that Poison's ratio for the current analysis is the same as that in [51]. Additionally, the shear modulus for each set of the laminate has been obtained via the general formula available in [52]:

$$
\left(G_{l t}=\frac{1}{\frac{4}{E_{45}}-\frac{1}{E_{l}}-\frac{1}{E_{t}}-\frac{2 v_{12}}{E_{l}}}\right) .
$$

Now, the vibration test is conducted using the homemade experimental set-up at parent Institute (NIT Rourkela), and the corresponding data are recorded via cDAQ-9178 (National Instruments). The instrument is an eight-channel compact data acquisition 
Table 2. Natural frequency $(\mathrm{Hz})$ of two-layered and four-layered symmetric angle-ply carbon/epoxy laminated composites flat panel under SFSF and CFFF support.

\begin{tabular}{|c|c|c|c|c|c|c|}
\hline \multirow{2}{*}{$\begin{array}{l}\text { Support } \\
\text { condition }\end{array}$} & \multirow{2}{*}{$\begin{array}{c}\text { Lamination } \\
\text { scheme }\end{array}$} & \multirow{2}{*}{$\begin{array}{c}\text { Mode } \\
\text { no. }\end{array}$} & \multicolumn{4}{|c|}{ Frequency $(\mathrm{Hz})$} \\
\hline & & & Experiment & Model-1 & Model-2 & Model-3 \\
\hline \multirow{10}{*}{ SFSF } & \multirow{5}{*}[\pm45^{\circ}]{} & 1 & 88 & 91.36 & 97.31531 & 90.403 \\
\hline & & 2 & 180 & 169.8 & 174.1709 & 169.34 \\
\hline & & 3 & 377 & 380.1 & 409.3941 & 364.75 \\
\hline & & 4 & 437 & 438.4 & 468.2937 & 435.7 \\
\hline & & 5 & 484 & 475.5 & 501.2964 & 463.28 \\
\hline & \multirow{5}{*}[\pm45^{\circ}]{$_{\mathrm{s}}$} & 1 & 161 & 165.577 & 175.1591 & 164.41 \\
\hline & & 2 & 307 & 319.80 & 326.2955 & 320.40 \\
\hline & & 3 & 667 & 683.90 & 730.8636 & 664.59 \\
\hline & & 4 & 827 & 817.30 & 869.75 & 815.80 \\
\hline & & 5 & 868 & 873.70 & 911.9091 & 862.04 \\
\hline \multirow{10}{*}{ CFFF } & \multirow{5}{*}[\pm45^{\circ}]{} & 1 & 33.5 & 32.79 & 35.45 & 32.58 \\
\hline & & 2 & 81.5 & 79.88 & 81.73 & 78.933 \\
\hline & & 3 & 210 & 207.38 & 217.93 & 200.67 \\
\hline & & 4 & 249 & 257.44 & 262.14 & 253.05 \\
\hline & & 5 & 302 & 296.73 & 308.84 & 287.93 \\
\hline & \multirow{5}{*}[\pm45^{\circ}]{$_{\mathrm{s}}$} & 1 & 62.5 & 60.07 & 63.96 & 59.77 \\
\hline & & 2 & 152 & 151.40 & 153.23 & 149.52 \\
\hline & & 3 & 378 & 371.47 & 383.40 & 362.75 \\
\hline & & 4 & 485 & 477.87 & 494.8 & 470.59 \\
\hline & & 5 & 561 & 549.98 & 562.36 & 536.25 \\
\hline
\end{tabular}

Table 3. Material properties.

\begin{tabular}{ccccc}
\hline Properties & $\begin{array}{c}\text { Material-1 } \\
(\mathbf{M} 1)\end{array}$ & $\begin{array}{c}\text { Material-2 } \\
(\mathbf{M} 2)\end{array}$ & $\begin{array}{c}\text { Material-3 } \\
(\mathbf{M} 3)\end{array}$ & $\begin{array}{c}\text { Material-4 } \\
\text { (M4) }\end{array}$ \\
\hline Young's modulus in $x$ direction $\left(E_{l}\right)$ & $40 E_{t}$ & $6.695 \mathrm{GPa}$ & $6.469 \mathrm{GPa}$ & $53.5 \mathrm{GPa}$ \\
Young's modulus in y direction $\left(E_{t}\right)$ & $1 \mathrm{GPa}$ & $6.314 \mathrm{GPa}$ & $5.626 \mathrm{GPa}$ & $2.1 \mathrm{GPa}$ \\
Young's modulus in $z$ direction $\left(E_{z}\right)$ & $E_{t}$ & $6.314 \mathrm{GPa}$ & $5.626 \mathrm{GPa}$ & $53.5 \mathrm{GPa}$ \\
Shear modulus $\left(G_{l t}\right)$ & $0.6 E_{t}$ & $2.7 \mathrm{GPa}$ & $2.05 \mathrm{GPa}$ & $1.05 \mathrm{GPa}$ \\
Shear modulus $\left(G_{t z}\right)$ & $0.5 E_{t}$ & $1.35 \mathrm{GPa}$ & $1.025 \mathrm{GPa}$ & $1.05 \mathrm{GPa}$ \\
Shear modulus $\left(G_{l z}\right)$ & $0.6 E_{t}$ & $2.7 \mathrm{GPa}$ & $2.05 \mathrm{GPa}$ & $1.05 \mathrm{GPa}$ \\
Poisson's ratio $\left(\nu_{l t}\right)$ & 0.25 & 0.17 & 0.17 & 0.25 \\
Poisson's ratio $\left(\nu_{l z}\right)$ & 0.25 & 0.17 & 0.17 & 0.25 \\
Poisson's ratio $\left(\nu_{t z}\right)$ & 0.25 & 0.17 & 0.17 & 0.25 \\
Density $(\rho)$ & $1900 \mathrm{kgm}^{-3}$ & $1900 \mathrm{kgm}^{-3}$ & $1900 \mathrm{kgm}^{-3}$ & $800 \mathrm{kgm}^{-3}$ \\
\hline
\end{tabular}

system that can be used for a variety of mechanical measurements (temperature, strain, load, pressure, torque, acceleration, and acoustics) and a pictorial form of the same, as presented in Figure 5(a). The frequency responses are recorded for the carbon/epoxy composite flat panel structure under SFSF support condition. Initially, the panel is excited with an electronic impact hammer at any arbitrary point on the structure (Figure 5(b)), and the output signal is sensed via an accelerometer mounted on the structural panel. The accelerometer is a type of sensor that captures the acceleration, converts it into an analogue voltage signal, and processes to a cDAQ where the analogue signal is further converted into digital signal via the 


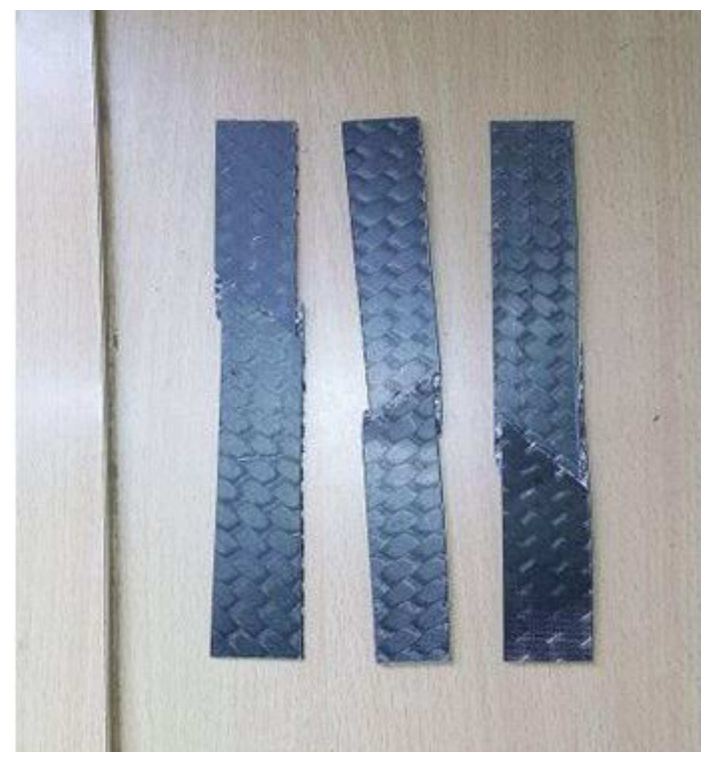

Figure 4(b). Carbon/epoxy composite flat panel specimen after tensile test.

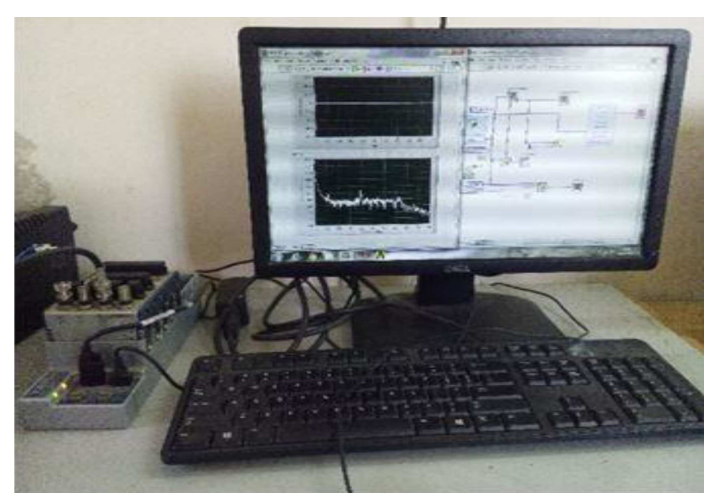

Figure 5(a). CDAQ 9178 national instruments and display.

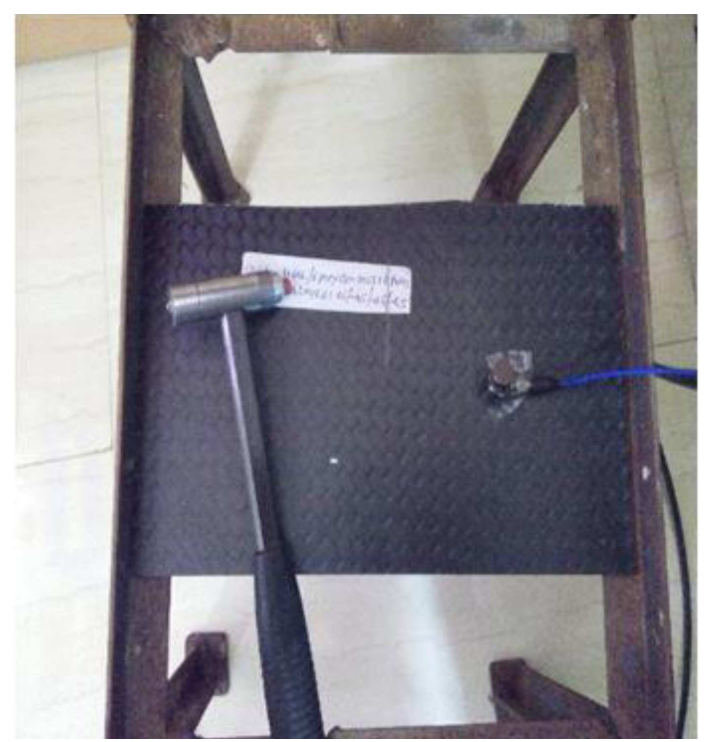

Figure 5(b). Experimental set-up for free vibration analysis. inbuilt analogue-digital converter. Now, the signal is processed further via a well-known signal processing software, named LABVIEW. The LABVIEW operates through three main panels: front panel, block diagram, and the connector panel. The front panel is also called the user interface panel where the recorded data can be seen in the form of a graph or numeric as per user's interest. Further, the block diagram, which is a programming window, and the necessary programming can be changed, called Virtual Instrument (VI). This can be performed to process the input signal and get the desired form of output. Herein, the block diagram is mainly used to capture the frequency responses of the laminate structure, whose details are provided in Figure 5(c). The input acceleration signal coming from the cDAQ now passes through a power spectrum module, as shown in the block diagram, to convert it into the time-domain and frequency-domain forms. The necessary frequency responses obtained from the acceleration signal are kept for the future use, i.e. validation purposes. Finally, the captured frequency responses of carbon/epoxy layered composite plate have been compared with the numerical and simulated responses computed from the proposed and ANSYS models, as shown in Table 2. The comparison study clearly indicates the accuracy and necessity of the current HSDT models (Model-1 and Model-2) instead of FSDT model, i.e. Model-3.

\subsection{Transient response}

Now, the present models are extended to compute the transient behaviour of three different flat panel cases. In the present comparison study, the transient behaviors of a single-layered orthotropic plate and a four-layered square angle-ply laminated composite plate with simply-supported edges are examined under uniformly distributed step load $\left(q_{0}=0.1 \mathrm{~N} / \mathrm{mm}^{2}\right)$ The transient responses are computed using the present numerical models (Model-1 and Model-2) as well as the simulation model ANSYS (Model-3) by setting the time step to $10 \mu \mathrm{s}$. For this analysis, the panel dimension of $250 \mathrm{~mm}$ length and $5 \mathrm{~mm}$ height is taken with M4 material properties, as given in Table 3. The transient responses of single-layer and four-layer angleply $\left( \pm 45^{\circ}\right)_{\mathrm{s}}$ layered composite panels are compared with the available published responses [53,54], as plotted in Figures 6(a) and 6(b), respectively. The figures clearly show that the responses are in close agreement with the previously reported responses.

\subsection{Numerical examples}

The convergence and validation results clearly indicate that the present developed HSDT models are capable enough to analyse the time-dependent deflection and vibration characteristics of the layered composite structure with adequate accuracy. Now, the models are 


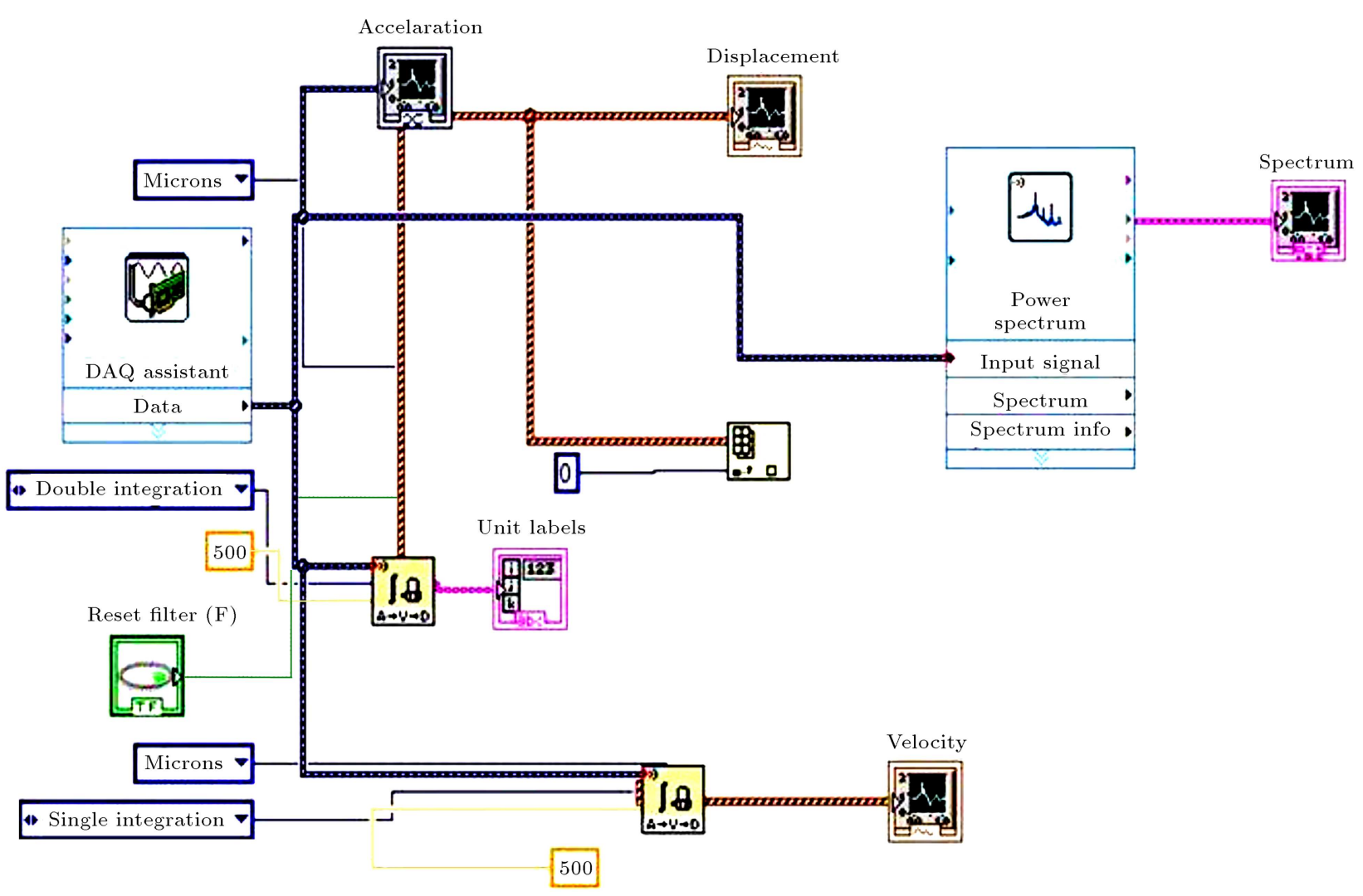

Figure 5(c). Block diagram of the LABVIEW software.

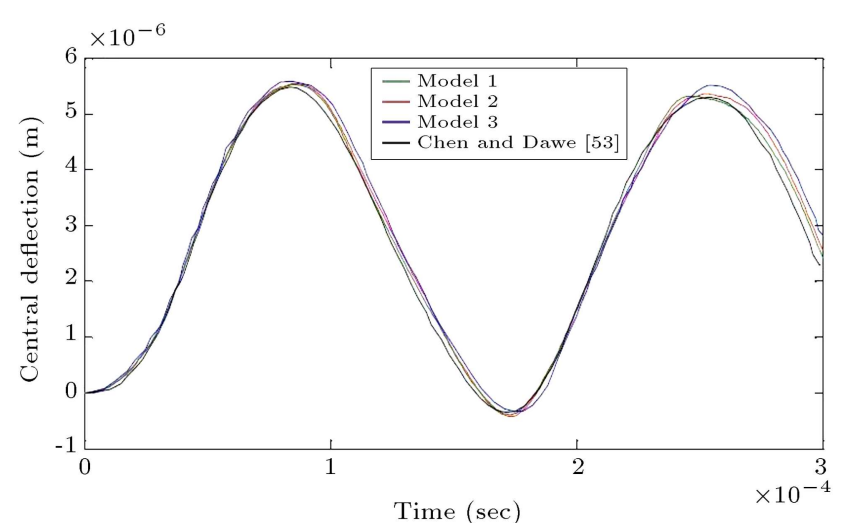

Figure 6(a). Central deflection versus time response of single-layered orthotropic laminated flat panel to a step load $\left(0.1 \mathrm{~N} / \mathrm{mm}^{2}\right)$.

utilised further to solve a new example to enhance the quantitative understanding on influence of the design parameters (the thickness ratios, the curvature ratios, the support conditions) on dynamic responses of the layered composite plate/shell structure.

\subsubsection{Influence of support conditions on fundamental frequency response}

It is well known that different support conditions of the composite structure affect the overall stiffness and, further, the structural responses significantly. In the current example, the influence of the support

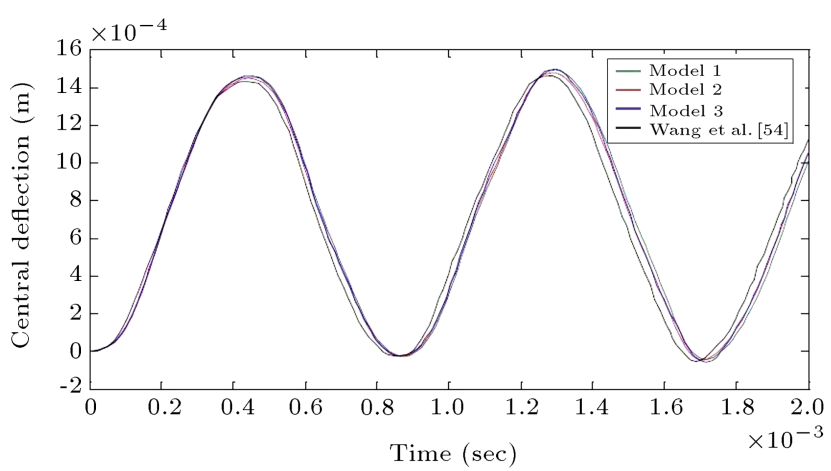

Figure 6(b). Central deflection versus time response of simply-supported four-layered angle-ply laminated flat panel to a step load $\left(0.1 \mathrm{~N} / \mathrm{mm}^{2}\right)$.

condition on frequency responses of the square fourlayer cross-ply laminated plates with M1 material properties has been investigated. The responses are evaluated for five different end conditions: CCCC (alledge clamped), SCSC (two-edge simply-supported and two-edge clamped), SSSS (all-edge simply-supported), CFCF (two-edge clamped and two-edge free), and CFFF (one-edge clamped and others free, i.e. cantilever) and five side-to-thickness ratios $(a / h=2,4$, 10, 20, 50, and 100) using Model-1 and presented in Figure 7. It is observed from the Figure that the nonlinear vibration responses are in the ascending order with CFFF, SSSS, SCSC, CFCF, and CCCC end 


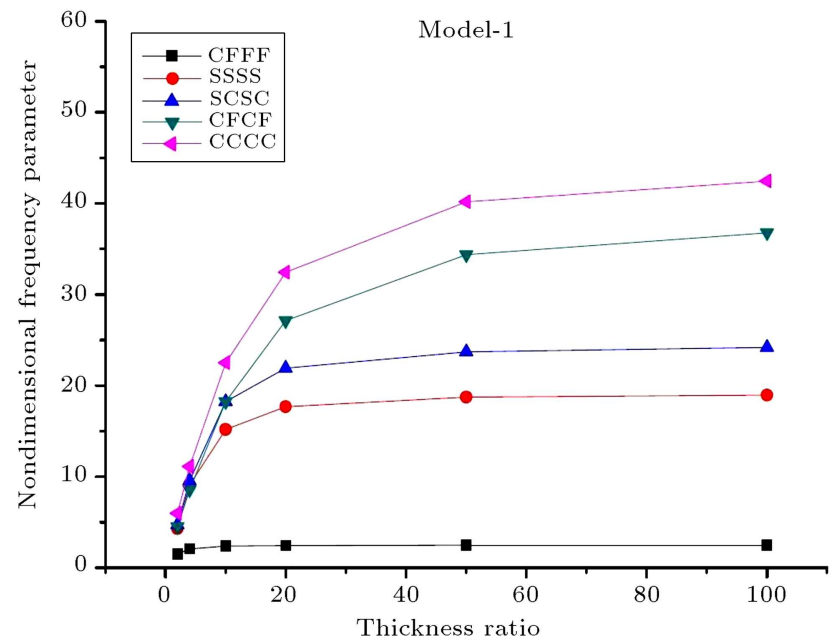

Figure 7. Effect of support conditions on the non-dimensional frequency of four-layered symmetric cross-ply laminated composite flat panel.

conditions irrespective of the side-to-thickness ratio. It is due to the increase in the overall stiffness with the increasing number of constraints.

\subsubsection{Influence of curvature ratio on fundamental frequency response}

The shell panel can be easily categorized into a deep or shallow shell panel, based on its curvature ratio. As the shell panel changes its geometry from shallow to deep, the stretching and bending energies change, i.e. the stretching energy becomes high compared to bending energy, which significantly affects the structural response. In this illustration, fundamental frequency responses of different shell panels (cylindrical, spherical, hyperboloid, and ellipsoid) with simply-supported boundaries have been analysed for fine different curvature ratio $(R / a=20$ to $40,60,80$ and 100) using Model-1, as presented in Figure 8 . The frequencies

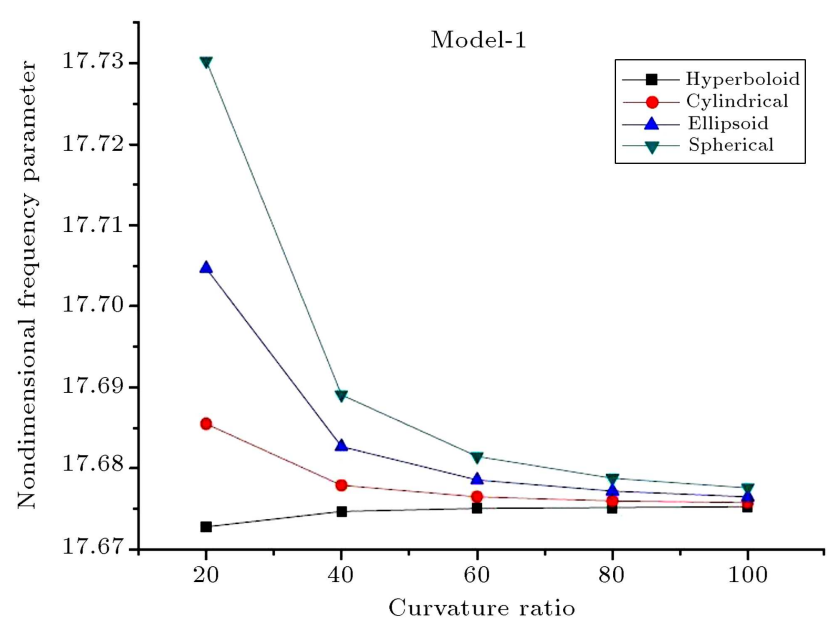

Figure 8. Effect of curvature ratio on the non-dimensional frequency of four-layered symmetric cross-ply laminated composite panel. of four-layer symmetric cross-ply layered composite structure are obtained with M1 material properties by taking $a / h=20$. It has been noted from the present example that the non-dimensional fundamental frequency responses are decreasing for each of shell geometries, except the hyperboloid panel due to the unequal curvature.

\subsubsection{Influence of aspect ratio on fundamental frequency response}

The aspect ratio $(a / b)$ of any structural component plays a major role in stiffness and stability behaviour and becomes more important for thin laminated curved panels. In this example, Model-1 is employed to calculate the natural frequency responses of the fourlayer symmetric cross-ply layered composite structure with simply-supported edges for five different aspect ratios $(a / b=1,1.5,2,2.5$, and 3$)$. The responses for all different geometries (hyperboloid, spherical, cylindrical, flat and ellipsoid) are computed utilising M1 composite properties and taking $a / h=50$ and $R / a$ $=5$, as presented in Figure 9 . It has been seen from the figure that the non-dimensional fundamental frequency values are increasing as the aspect ratio increases for each of the shell geometries. However, the differences between the results become insignificant after $a / b=$ 2 for each of shell geometries, except the flat panel case. It has also been noticed that the highest and lowest frequencies are obtained for the spherical and flat panels, respectively.

\subsubsection{Influence of shell geometry on fundamental frequency response}

In this illustration, the influence of the shell panel geometries (hyperboloid, flat, spherical, cylindrical, and ellipsoid) on the free vibration responses of laminated composite structure is investigated. For the investiga-

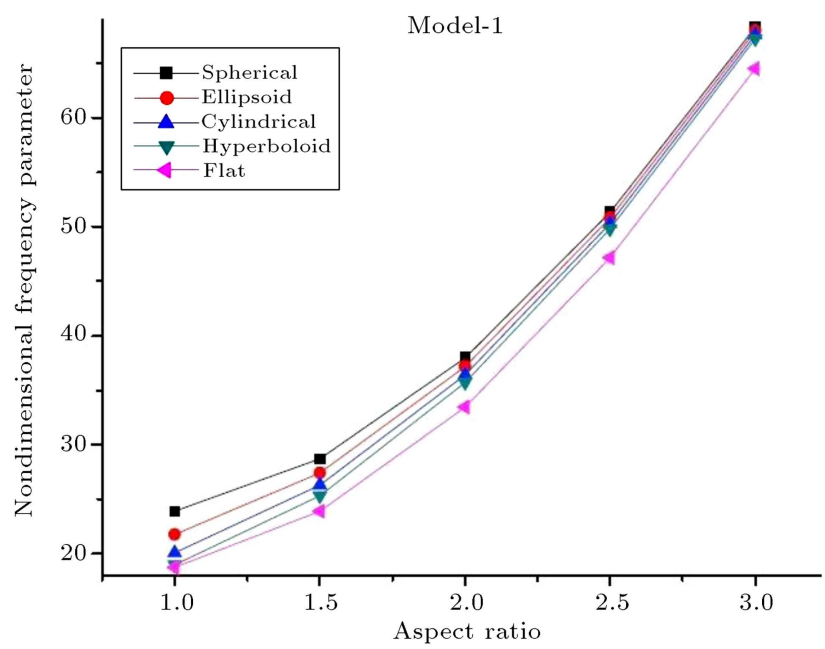

Figure 9. Effect of aspect ratio on the non-dimensional frequency of four-layered symmetric cross-ply laminated composite panel. 


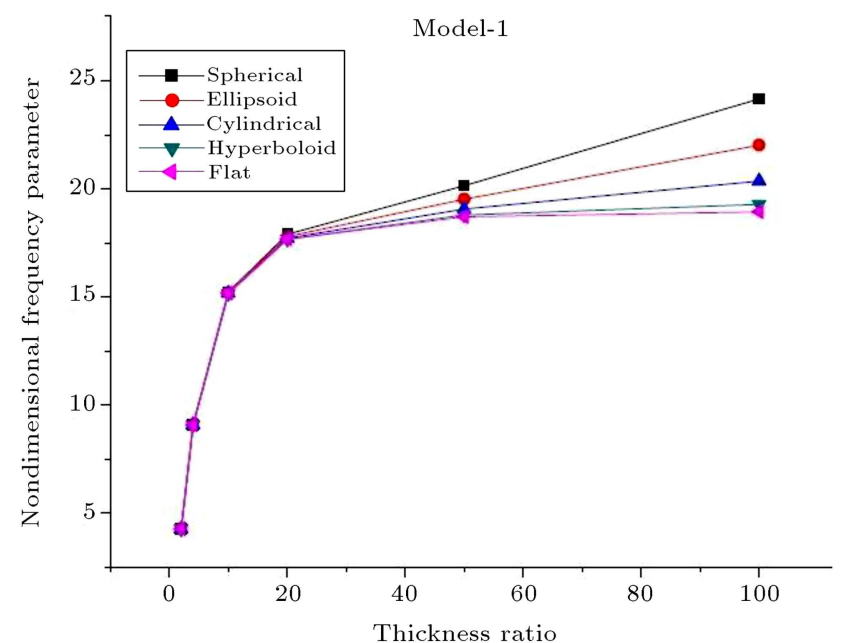

Figure 10. Effect of shell geometry on the non-dimensional frequency of four-layered symmetric cross-ply laminated composite panel $(R / a=10)$.

tion, the frequencies of simply-supported square fourlayer cross-ply symmetric layered composite panel $(R / a$ $=10)$ with M1 material properties are obtained for six different thickness ratios $(a / h=2,4,10,20,50$, and 100), as depicted in Figure 10. It has been observed from the figure that the variations of the responses are insignificant for thick laminates $(a / h=2,4$, and $10)$, whereas the differences are pronounced for thin panels $(a / h=20,50$ and 100$)$. In addition, it has been observed that the maximum frequencies are obtained for the spherical geometry, and the least frequency is obtained for the flat panels.

\subsubsection{Influence of thickness ratio on time-dependent deflection response}

This example has been solved to obtain the timedependent deflection responses of the square, simplysupported four-layer angle-ply $\left( \pm 45^{\circ}\right)_{\mathrm{s}}$ layered composite panel. The mentioned responses are obtained using Model-1 for five different thickness ratios $(a / h=30$, $35,40,45$, and 50) with M4 material properties under the uniform step loading of $0.1 \mathrm{~N} / \mathrm{mm}^{2}$, as presented in Figure 11. It is observed from the figure that the time-dependent displacement response increases as the thickness ratio increases; thus, the responses' frequencies decrease.

\subsubsection{Influence of shell geometries on transient behaviour}

The time-dependent transverse central deflection responses of different layered composite shell panels (hyperboloid, cylindrical, flat, ellipsoid, and spherical) are examined in the current example. The responses are calculated for square, simply-supported four-layer angle-ply $\left( \pm 45^{\circ}\right)_{\mathrm{s}}$ layered composite structure $(R / a=$ $10, a / h=50)$ under the uniform step loading of 0.1 $\mathrm{N} / \mathrm{mm}^{2}$ through the use of Model-1 and M4 properties.

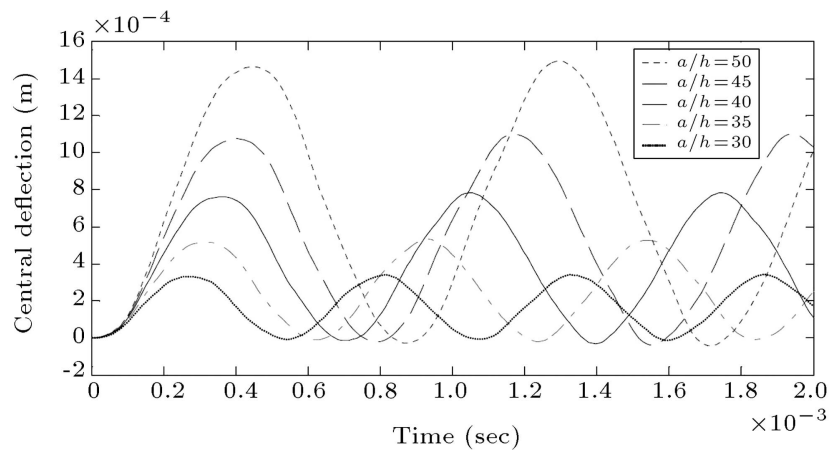

Figure 11. Effect of thickness ratio on the central deflection of simply-supported four-layered angle-ply laminated flat panel.

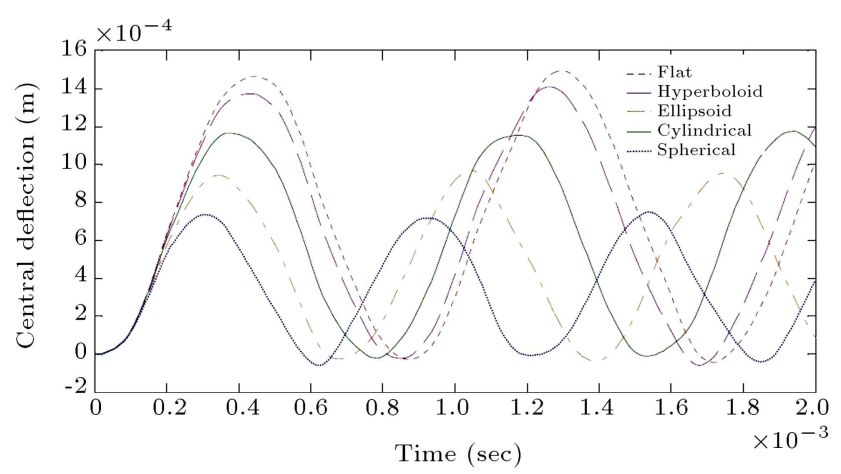

Figure 12. Effect of curvature ratio on the central deflection of simply-supported four-layered angle-ply laminated flat panel.

The calculated responses are presented in Figure 12. The figure shows that the central deflection responses are at maximum for flat panel and at minimum for the spherical shell panel. In addition, it is inferred that the responses of the hyperboloid and flat panel are close to each other in a few instances of time.

\section{Conclusions}

The fundamental frequency and transient behaviour of the carbon/epoxy layered composite flat/curved shallow shell panels were investigated numerically by developing two FE models in HSDT kinematic. Further, a MATLAB code was prepared based on the proposed models to compute the numerical responses and compare them with the subsequent experimental responses. In addition, a simulation model in ANSYS software was developed, and the response obtained using simulation software was also compared with that of the present experimental and numerical results. The validity of the proposed models was also checked by comparing the present numerical results with the result of the published literature. Additionally, the importance of the present models and the influences of the different design parameter were illustrated by solving a new numerical illustration. Based on the 
convergence, validation, and parametric study, the following conclusions were drawn and discussed below:

a) The convergence and validation study of the proposed HSDT models clearly indicate that the presented models are suitable for the fundamental frequency and time dependent-deflection response of the layered composite flat/curved shallow shell structure;

b) The parametric studies show that different geometries of the shell panel considerably affect both vibration and transient responses;

c) The fundamental frequencies are at maximum for the spherical and at minimum for the plate structure. In addition, the time-dependent deflection responses are at maximum for the plate and at minimum for the layered spherical composite structure;

d) The side-to-thickness ratio, constraint conditions, curvature ratio, and aspect ratio affect the fundamental frequency and time-dependent transverse deflection of the flat/curved shallow shell panel significantly.

\section{Acknowledgements}

This work is under the project sanctioned by the Department of Science and Technology (DST) through grant SERB/F/1765/2013-2014 Dated: 21/06/2013. Authors are grateful to DST, Govt. of India for their consistent support.

\section{References}

1. Mallikarjuna, B. and Kant, T. "Dynamics of laminated composite plates with a higher order theory and finite element discretization", J. Sound and Vibr., 126(3), pp. $463-475$ (1988).

2. Chakravorty, D., Bandyopadhyay, J.N., and Sinha, P.K. "Finite element free vibration analysis of doubly curved laminated composite shells", J. Sound and Vibr., 191(4), pp. 491-504 (1996).

3. Chakraborty, S. and Mukhopadhyay, M. "Free vibrational responses of FRP composite plates: Experimental and numerical studies", J. Reinf Plast Comp., 19(7), pp. 535-551 (2000).

4. Ahmadain, M.T. and Zangeneh, M.S. "Forced vibration analysis of laminated rectangular plate using super element", Scientia Iranica, 10(2), pp. 260-265 (2003).

5. Kant, T. and Swaminathan, K. "Analytical solutions for free vibration of laminated composite and sandwich plates based on higher order refined theory", Compos. Struct., 53, pp. 73-85 (2001).
6. Mantari, J.L., Oktem, A.S., and Soares, C.G. "Static and dynamic analysis of laminated composite and sandwich plates and shells by using a new higher-order shear deformation theory", Compos. Struct., 94, pp. 37-49 (2011).

7. Cugnoni, J., Gmur, T., and Schorderet, A. "Identification by modal analysis of composite structures modelled with FSDT and HSDT laminated shell finite elements", Compos: Part A., 35, pp. 977-987 (2004).

8. Tornabene, F., Viola, E., and Fantuzzi, N. "General higher-order equivalent single layer theory for free vibrations of doubly-curved laminated composite shells and panels", Compos. Struct., 104, pp. 94-117 (2013).

9. Jeyaraj, P., Padmanabhan, C., and Ganesan, N. "Vibration and acoustic response of an isotropic plate in a thermal environment", ASME J. Vib Acoust., 130(5), p. 051005 (2008).

10. Mehar, K., Panda, S.K., Dehengia, A., and Kar, V.R. "Vibration analysis of functionally graded carbon nanotube reinforced composite plate in thermal environment", J. of Sandw. Struct. and Mater., 18(2), pp. 151-173 (2015).

11. Ghafoori, E. and Asghari, M. "Dynamic analysis of laminated composite plates traversed by a moving mass based on a first-order theory", Compos. Struct., 92, pp. 1865-1876 (2010).

12. Maleki, S., Tahani, M., and Andakhshideh, A. "Transient response of laminated plates with arbitrary laminations and boundary conditions under general dynamic loadings", Arch. Appl. Mech., 82, pp. 615630 (2012).

13. Diacenco, A., Jorge, A.B. and Silva, P. "Dynamic analysis of the influence of fiber orientation in composite laminated plates", J. Mech. Eng. Res., 7(1), pp. 1-8 (2015).

14. Shokrollahi, S. and Shafaghat, S. "A global Ritz formulation for the free vibration analysis of hybrid metal-composite thick trapezoidal plates", Scientia Iranica B., 23(1), pp. 249-259 (2016).

15. Kerur, S.B. and Ghosh, A. "Active vibration control of composite using AFC actuator and PVDF sensor", J. Intel Mat. Syst. Str., 22(11), pp. 1149-1160 (2011).

16. Kumar, J.S., Raju, T.D., and Reddy, K.V.K. "Vibration analysis of composite laminated plates using higher-order shear deformation theory with zig-zag function", Indian J Sci Technol, 4(8), pp. 960-966 (2011).

17. Eruslu, S.O. and Aydogdu, M. "Free vibration analysis of short fiber reinforced laminated plates with first shear deformation theory", Turkish J. Eng. Env. Sci., 36, pp. 95-107 (2012).

18. Sahoo, S.S., Panda, S.K., and Mahapatra, T.R., "Static, free vibration and transient response of laminated composite curved shallow panel - An experimental approach", Eur. J. Mech. A-Solid., 59, pp. 95-113 (2016). 
19. Hirwani, C.K., Patil, R.K., Panda, S.K., Mahapatra, S.S., Mandal, S.K., Srivastava, L., and Buragohain, M.K. "Experimental and numerical analysis of free vibration of delaminated curved panel", Aerosp. Sci. Technol., 54, pp. 353-370 (2016).

20. Li, J., Huo, Q., Li, X., Kong, X., and Wu, W. "Vibration analyses of laminated composite beams using refined higher-order shear deformation theory", Int. J. Mech. Mater. Des., 10, pp. 43-52 (2014).

21. Bessaim, A., Houari, M.S.A., Tounsi, A., Mahmoud, S.R., and Adda Bedia, E.A. "A new higher-order shear and normal deformation theory for the static and free vibration analysis of sandwich plates with functionally graded isotropic face sheets", J. Sandw. Struct. Mater., 15, pp. 671-703 (2013).

22. Bouderba, B., Houari, M.S.A., and Tounsi, A. "Thermomechanical bending response of FGM thick plates resting on Winkler-Pasternak elastic foundations", Steel and Compos. Struct., 14(1), pp. 85-104 (2013).

23. Zidi, M., Tounsi, A., Houari, M.S.A., and Bég, O.A. "Bending analysis of FGM plates under hygro-thermomechanical loading using a four variable refined plate theory", Aerospace Sci. Tech., 34, pp. 24-34 (2014).

24. Fekrar, A., Houari, M.S.A., Tounsi, A., and Mahmoud, S.R. "A new five-unknown refined theory based on neutral surface position for bending analysis of exponential graded plates", Meccanica, 49, pp. 795-810 (2014).

25. Belabed, Z., Houari, M.S.A., Tounsi, A., Mahmoud, S.R., and Anwar Bég, O. "An efficient and simple higher order shear and normal deformation theory for functionally graded material (FGM) plates", Compos: Part B., 60, pp. 274-283 (2014).

26. Bourada, M., Kaci, A., Houari, M.S.A., and Tounsi, A. "A new simple shear and normal deformations theory for functionally graded beams", Steel and Compos. Struct., 18(2), pp. 409-423 (2015).

27. Ait Yahia, S., Ait Atmane, H., Houari, M.S.A., and Tounsi, A. "Wave propagation in functionally graded plates with porosities using various higher-order shear deformation plate theories", Struct. Eng. Mech., 53(6), pp. 1143-1165 (2015).

28. Tounsi, A., Houari, M.S.A., and Bessaim, A. "A new 3-unknowns non-polynomial plate theory for buckling and vibration of functionally graded sandwich plate", Struct. Eng. Mech., Int. J., 60(4), pp. 547-565 (2016).

29. Bennoun, M., Houari, M.S.A., and Tounsi, A. "A novel five variable refined plate theory for vibration analysis of functionally graded sandwich plates", Mech. Adv. Mater. Struc., 23(4), pp. 423-431 (2016).

30. Bouderba, B., Houari, M.S.A., Tounsi, A., and Hassan, S. "Thermal stability of functionally graded sandwich plates using a simple shear deformation theory", Struct. Eng. Mech., 58(3), pp. 397-422 (2016).

31. Bellifa, H., Benrahou, K.H., Hadji, L., Houari, M.S.A., and Tounsi, A. "Bending and free vibration analysis of functionally graded plates using a simple shear deformation theory and the concept the neutral surface position", J. Braz. Soc. Mech. Sci. Eng., 38(1), pp. 265-275 (2016).

32. Bousahla, A.A., Benyoucef, S., Tounsi, A., and Hassan, S. "On thermal stability of plates with functionally graded coefficient of thermal expansion", Struct. Eng. Mech., 60(2), pp. 313-335 (2016).

33. Draiche, A., Tounsi, A., and Hassan, S. "A refined theory with stretching effect for the flexure analysis of laminated composite plates", Geomech and Eng., 11(5), pp. 671-690 (2016).

34. Chikh, A., Tounsi, A., Habib, H., and Hassan, S. "Thermal buckling analysis of cross-ply laminated plates using a simplified HSDT", Smart. Struct. Syst., 19(3), pp. 289-297 (2017).

35. Tounsi, A., Houari, M.S.A., Benyoucef, S., and Adda Bedia, E.A. "A refined trigonometric shear deformation theory for thermoelastic bending of functionally graded sandwich plates", Aerospace Sci. Tech., 24, pp. 209-220 (2013).

36. Draiche, K., Tounsi, A., and Khalfi, Y. "A trigonometric four variable plate theory for free vibration of rectangular composite plates with patch mass", Steel Compos. Struct., 17(1), pp. 69-81 (2014).

37. Beldjelili, Y., Tounsi, A., and Mahmoud, S.R. "Hygrothermo-mechanical bending of S-FGM plates resting on variable elastic foundations using a four-variable trigonometric plate theory", Smart Struct. Syst., Int. $J .$, 18(4), pp. 755-786 (2016).

38. Hamidi, A., Houari, M.S.A., Mahmoud, S.R., Tounsi, A. "A sinusoidal plate theory with 5-unknowns and stretching effect for thermomechanical bending of functionally graded sandwich plates", Steel and Compos. Struct., 18(1), pp. 235-253 (2015).

39. Houari, M.S.A., Tounsi, A., Bessaim, A., and Mahmoud, S.R. "A new simple three-unknown sinusoidal shear deformation theory for functionally graded plates", Steel and Compos. Struct., 22(2), pp. 257-276 (2016).

40. Hebali, H., Tounsi, A., Houari, M.S.A., Bessaim, A., and Bedia, E.A.A. "A new quasi-3D hyperbolic shear deformation theory for the static and free vibration analysis of functionally graded plates", ASCE J. Eng. Mech., 140, pp. 374-383 (2014).

41. Mahi, A., Adda Bedia, E.A., and Tounsi, A. "A new hyperbolic shear deformation theory for bending and free vibration analysis of isotropic, functionally graded, sandwich and laminated composite plates", Appl. Math. Model., 39, pp. 2489-2508 (2015).

42. Shooshtari, A. and Razavi, S. "Large-amplitude free vibration of magneto-electro-elastic curved panels", Scientia Iranica B., 23(6), pp. 2606-2615 (2016).

43. Milan, Z., Josef, S., Lenka, R., and Jan, S. "Finite element transient dynamic analysis of laminated com- 
posite plates", Appl. Mech. Mater., 732, pp. 357-364 (2015).

44. Reddy, J.N., Mechanics of Laminated Composite Plates and Shells", 2nd Ed., Florida, CRC Press (2004).

45. Szekrenyes, A. "Analysis of classical and first-order shear deformable cracked orthotropic plates", J. Compos. Mater., 48(12), pp. 1441-1457 (2013).

46. Bathe, K.J., Finite Element Procedures in Engineering Analysis, New Jersey, Prentice-Hall (1982).

47. Whitney, J.M. and Pagano, N.J. "Shear deformation in heterogeneous anisotropic plates", J. Appl. Mech., 37(4), pp. 1031-1036 (1970).

48. Reddy, J.N. "A simple higher order theory for laminated composite plates", J. Appl. Mech., 51, pp. 745752 (1984)

49. Senthilnathan, N.R., Lim, K.H., and Chow, S.T. "Buckling of shear deformation plate", AIAA, 25(9), pp. 1268-1271 (1987).

50. ASTM D 3039/D 3039M, Standard Test Method for Tensile Properties of Polymer Matrix Composite Materials (2006).

51. Crawley, E.F. "The natural modes of graphite/epoxy cantilever plates and shells", J. Compos. Mater., 13, pp. 195-205 (1979).

52. Jones, R.M., Mechanics of Composite Materials, 2nd Ed., Philadelphia, Taylor and Francis (1975).

53. Chen, J., Dawe, D.J., and Wang, S. "Nonlinear transient analysis of rectangular composite laminated plates", Compos. Struct., 49, pp. 129-139 (2000).

54. Wang, S., Chen, J., and Dawe, D.J. "Linear transient analysis of rectangular laminates using spline finite strips", Compos. Struct., 41, pp. 57-66 (1998).

\section{Biographies}

Sushreee Sasmita Sahoo completed MTech (Research) from the Department of Mechanical Engineering NIT, Rourkela. Her skills and expertise include laminated composites, finite-element analysis pertaining to mechanical behaviour of composite materials, and experimental vibration analysis.

Chetan Kumar Hirwani is pursuing his $\mathrm{PhD}$ at the Department of Mechanical Engineering, NIT, Rourkela. He has been working on the nonlinear behaviour of delaminated composite plates/shells since the last one and half year via experimental and numerical study of different kinds of advanced composite components including the simulation. His area of interest is finite-element analysis of damaged modelling of laminated composite plate and shell structures.

Subrata Kumar Panda received his $\mathrm{PhD}$ degree from IIT Kharagpur, India in 2009. He is working as an Assistant Professor at the Department of Mechanical Engineering, NIT, Rourkela. His current research interests include nonlinear solid mechanics, smart composite structures, nonlinear FEM, experimental vibrations, functionally graded materials, SMA, PZT and magnetostrictive material, bio-mechanical analysis of functional materials.

Deeprodyuti Sen completed MTech from the Department of Mechanical Engineering NIT, Rourkela. His areas of interests are finite-element modelling and analysis of the mechanical behaviour of composite structure such as layered and nano composites. 